\title{
The Irish World Music Café: Performing and Recording as Tools for Sustainable Social Integration
}

\author{
Helen Phelan ${ }^{12 *}$, Julianne Hennell ${ }^{2}$, Dominic Chappell ${ }^{3}$, Andrew Nathan Roberts ${ }^{4}$ \\ 1 Irish World Academy of Music and Dance, University of Limerick \\ 2 Sanctuary and Singing \& Sustainable Social Integration Research Project \\ 3 Learning Hub, Limerick \\ 4 School of Culture and Communication, University of Limerick \\ *helen.phelan@ul.ie
}

Received: 7 June 2017 ; Accepted: 29 September 2017 ; Published: 1 November 2017

Editor: Michael Viega Reviewers: Michele Forinash, Dorothea Pienaar

\begin{abstract}
This arts-based and ethnographic research comprises two video submissions; 'Elikya' and 'Irish World Music Café' as well as an accompanying paper exploring the potential contribution of live musical performance and video recording to sustainable social integration for new migrant communities. The research is anchored in an exploration of an initiative called The Irish World Music Café in Limerick city, Ireland. The café is a community-based event promoting social singing for new migrants and Limerick residents in the heart of the city. The paper discusses the growing body of evidence concerning the role played by music (particularly singing) in supporting sustainable social integration. It also presents two video-based projects: the first captures the live performances of the cafe with the second focusing on Elikya, a Congolese music group associated with the café. The paper also discusses the growing importance of video documentation in supporting and disseminating live performance events such as the café. Using Turino's categories of cultural formations and cultural cohorts (2008), it argues for the role of the café, both as a live event and a recorded phenomenon, in contributing to the development of alternative values and social change.
\end{abstract}

Keywords: Singing, Social Singing, Video Recording, Migrant, Intergation

\section{Video Submissions}

Elikya Choir

Irish World Music Café

\section{Introduction}

This arts-based research comprises two video submissions and an accompanying paper examining the role of live musical performance and video recording in contributing to sustainable social integration for new migrant communities. The research is anchored in an exploration of an initiative called The Irish World Music Café in Limerick city, Ireland. The café is a community-based event promoting social singing for new mi- 
grants and Limerick residents in the heart of the city. The Irish World Music Café is part of a wider research project called Singing and Sustainable Social Integration ${ }^{1}$ which supports and researches song-based projects linked to new migrant communities.

This paper discusses the growing body of evidence concerning the role played by music (particularly singing) in supporting sustainable social integration, primarily through the facilitation of identity-negotiation, social bonding, experiences of well-being, and self esteem in new cultural environments. It discusses the development of the Irish World Music Café in this context.

Over the course of the last year, the café has attracted two video-based projects: the first captures the live performances of the café with the second focusing on Elikya, a Congolese music group associated with the café. The paper also discusses the growing importance of video documentation in supporting and disseminating live performance events such as the café. Using Turino's categories of cultural formations and cultural cohorts (2008), it argues for the role of the café, both as a live event and a recorded phenomenon, in contributing to the development of alternative values and social change.

\section{Methodological Considerations}

The authors of this submission are videographers, musicians, and researchers. As the lead researcher on the Singing and Sustainable Social Integration project and first author, I agreed to contribute the written component (Phelan, 2017). My own background is strongly ethnographic, specializing in ethnographies of ritual communities and their music (Phelan, 2001, 2006, 2007, 2008, 2009, 2012, 2017). A key formative moment in my engagement with arts-based research occurred in 2002. I was working with a women's choir, which included members from the asylum seeking community in Ireland. As an ethnographer, I asked a number of women if I could interview them about their participation. I have always remembered the response of one of the women who told me that the last time she was interviewed, she had been in a police interrogation session. Why did I need to ask questions, she wondered? Was it not enough to sing together? The unintended challenge in her query led me to ask questions about the relationship between my research and artistic practices, nudging me towards an investigation of arts-based research: "[D]rawing on the capabilities of the creative arts, ABR practices offer qualitative researchers alternatives to traditional research methods and methodologies" (Leavy, 2009, ix.). This journey led to the production of a documentary film on the music of the choir (Phelan, 2002) and a nascent interest in film as a form of arts-based research.

Since 2009, I have also been the programme leader of a $\mathrm{PhD}$ in Arts Practice at the Irish World Academy of Music and Dance. 'Arts Practice' is a term used increasingly in Ireland and other parts of the work to denote practice-based research with an artistic specialization. ${ }^{2}$ This form of research often combines qualitative engagement with artistic processes (using, for example ethnographic, autoethnographic, and narrative approaches) as well as the artistic processes themselves. The written investigation does not explain the aesthetic processes, which are understood to engage in data collection, framing, interpreting and analyzing in their own right, but provides a resonant, theoretically driven, empathetic process of presentation and interpretation (Bannerman, Sofaer \& Watts, 2006).

This understanding of arts practice research has influenced our approach to this submission in its combination of music, film, ethnographic interview, and theoretical discourse. The written text does not attempt to interpret the music or film-making, but to create a resonant, ethnographic discussion around their interpretive and presentational tropes: in this case, the valuing and celebrating of alternative cultural cohorts and their contribution to social integration. 


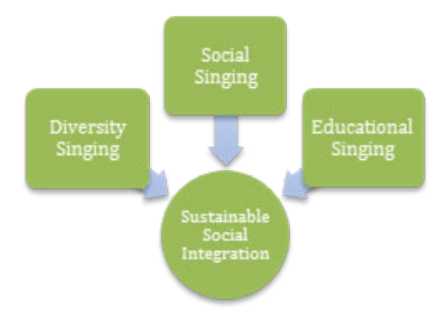

Figure 1. A Model of Singing for Sustainable Social Integration

\section{Singing and Sustainable Social Integration}

According to Global Trends, a report of the United Nations Refugee Agency, there are more than 65 million people currently displaced across the world. This is the largest number in recorded history. Approximately one per cent of the global population is an asylum seeker, a refugee, or a forcibly displaced migrant. This international migration crisis raises profound humanitarian issues around integration. While singing may not immediately leap to mind as a way of addressing this challenge, there is growing evidence that it is one of the more sustainable and accessible cultural activities to assist with integration (Ahlquist, 2006; Cohen et al. 2009; Phelan, 2017; Welch et al., 2014).

Much of this research focuses on how singing facilitates social bonding (Ford, 2003; Grape et al., 2003; Phelan, 2009, Weinstein et al., 2016). In an evolutionary sense, humans have created and maintained larger social groups than most of their primate relatives and ancestors. Group music making has been seen to increase feelings of social inclusion, connectivity, positive affect and endorphin release, fostering a sense of social closeness. Importantly, in the context of migration, this is seen to be the case even when the group becomes larger and more diverse. Group singing activates particular behaviours and responses. When singing in a group, for example, singers will modify their individual 'best tone' (formant) for the sake of creating a more satisfying group tone. In this sense, the individual accommodates difference but dialogues with it to create a sense of sonic affinity. Singing can therefore create a sense of temporal inclusion even in political environments where civic belonging is ambivalent or refused.

Research also demonstrates that access to musical experiences from a culture of origin can help migrants feel more at home in a new environment (Jäncke, 2008; Parncutt \& Dorfer, 2011; Phelan, 2012). Music promotes intercultural contact in a way that is often more accessible than language, arouses curiosity and interest, and creates a social atmosphere. Music is also very efficacious in arousing memory and emotion, allowing access to former experiences, as well as the emotional and psychological space to integrate these into new environments.

There is also a great deal of research concerning the educational value of music and singing as tools of social inclusion (Odena, 2009; Welch et al., 2014). Children with access to high quality singing education not only demonstrate higher singing ability but also more positive self-identity and self-esteem, feelings of well-being, and a sense of social inclusion. Studies also show that singing can assist language acquisition, group work, and communication skills.

Building on this research, the Singing \& Sustainable Social Integration initiative identified three core elements of singing, which contributed to sustainable social integration. These include:

- Social Singing: singing and/or listening to music in informal, socially integrated contexts.

- Diversity Singing: singing to express and transmit diverse cultural practices.

- Educational Singing: singing as a medium through which integration skills (such as language) may be taught.

The Irish World Music Café is an initiative that integrates all these aspects of singing. 


\section{The Irish World Music Café}

In October, 2015, Doras Luimní ${ }^{3}$ called an open meeting in response to the European migration crisis. One of the outcomes of this meeting was the identification of key events/initiatives designed to provide opportunities for new migrants to meet Irish people. The Irish World Academy of Music and Dance at the University of Limerick has a long track record of supporting culturally-based projects with new migrant communities through its Sanctuary outreach programme. ${ }^{4}$ The Irish World Music Café emerged in response to the open meeting following talks between Doras Luimní and the Academy. Commencing in May, 2016, it is a lunchtime, monthly gathering of people in Limerick for an open mic style music session with tea, coffee, cold drinks, and sandwiches. Doras Luimní's offices are located in Central Buildings on O'Connell Street, the main street of Limerick city. The cafés take place in cb1,a community café and art gallery located in the same building and supported by the Central Buildings Community Project. The noon starting time coincides with the end time of English language classes for new migrants coordinated by Doras Luimní in the same building. Many of the participants come directly from class to have lunch and share in some singing and music-making.

Lylian Fatabong, a journalist from Cameroon now living in Ireland, has first hand experience of the asylum seeking process in Ireland. Since receiving refugee status, she has completed a Masters in Journalism at the University of Limerick and regularly reports on migrant issues in Ireland. Her report on the first Irish World Music Café featured Zimbabwean born Felix Dzamara. Felix arrived in Ireland three years ago as an asylum seeker and recounted his experience of participating in a series of community music workshops, culminating in the performance of the group's first single at the café:

For three years, I was idle in the hostel, I had nowhere to go to and very little to do, but the music workshop came along and helped me to meet, sing and integrate with people of different cultures, and on Thursday, we were able to showcase our singing talent through our first music single ...this gives me a sense of belonging that, well, I now belong in Limerick; I am now a part and parcel of Limerick and we are contributing some form of entertainment in Limerick. ${ }^{5}$

The café features singers from new migrant communities, students from the Irish World Academy of Music and Dance at the University of Limerick, and singers from a number of community-based projects including a community music workshop for newcomers. The role social singing has played in traditional Irish society (Thacker, 2012; O'Shea, 2007; Ó Laoire, 1997) is well documented and the café is also supported by a number of well-known Irish traditional musicians from the local community.

\section{Live Performance and Video Recording}

Following its inception in May, 2016 two video-projects related to the café were undertaken. These two projects form the arts-based aspect of this submission.

Since Vogel's (1974) groundbreaking publication Film as a Subversive Art, much has been written about the interface between recording and live performance. In his 2008 publication Music as Social Life, ethnomusicologist Thomas Turino categorized music making into four main areas consisting of two contrasting sets of practices. Participatory and presentational music refers to music where, on the one hand, there is no distinction between artist and audience and on the other, a separation of identity into those who make music for those who do not. The second set of categories refers to technology. High Fidelity Recording involves recordings of live performances while Studio Audio Art is the creation of a recorded art object, not the capturing of live sound.

Even in the short period since Turino's publication, there has been wide-scale erosion of the boundaries between these proposed classifications. One of the key ways in which audiences (or collaborative performers) participate in concerts (presentational music) is to record them. These recordings often capture both the live event (high fidelity recording) but may also be highly edited with personal apps to create studio audio art. 


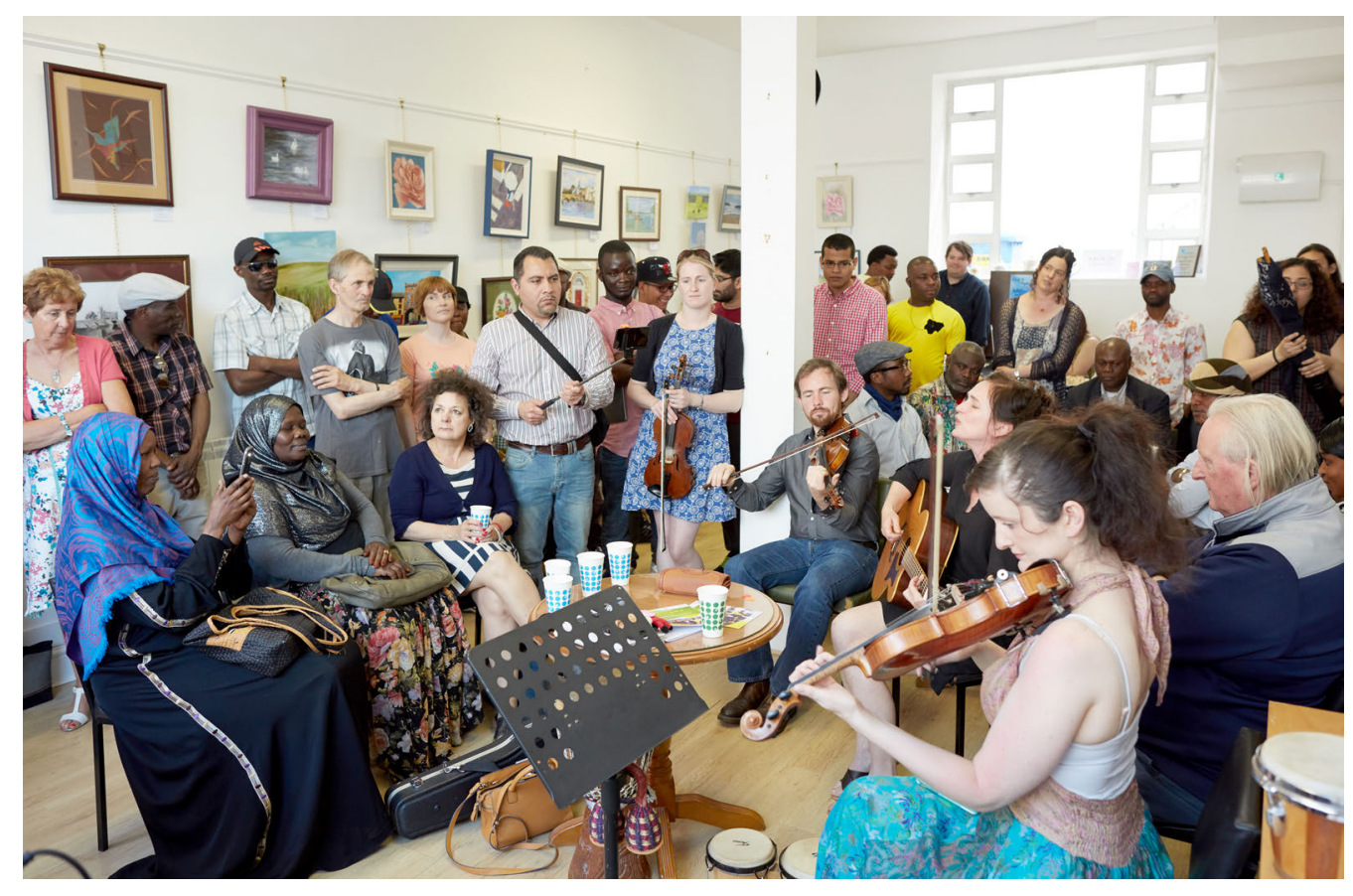

Figure 2. Irish World Music Café

(Photograph by Maurice Gunning)

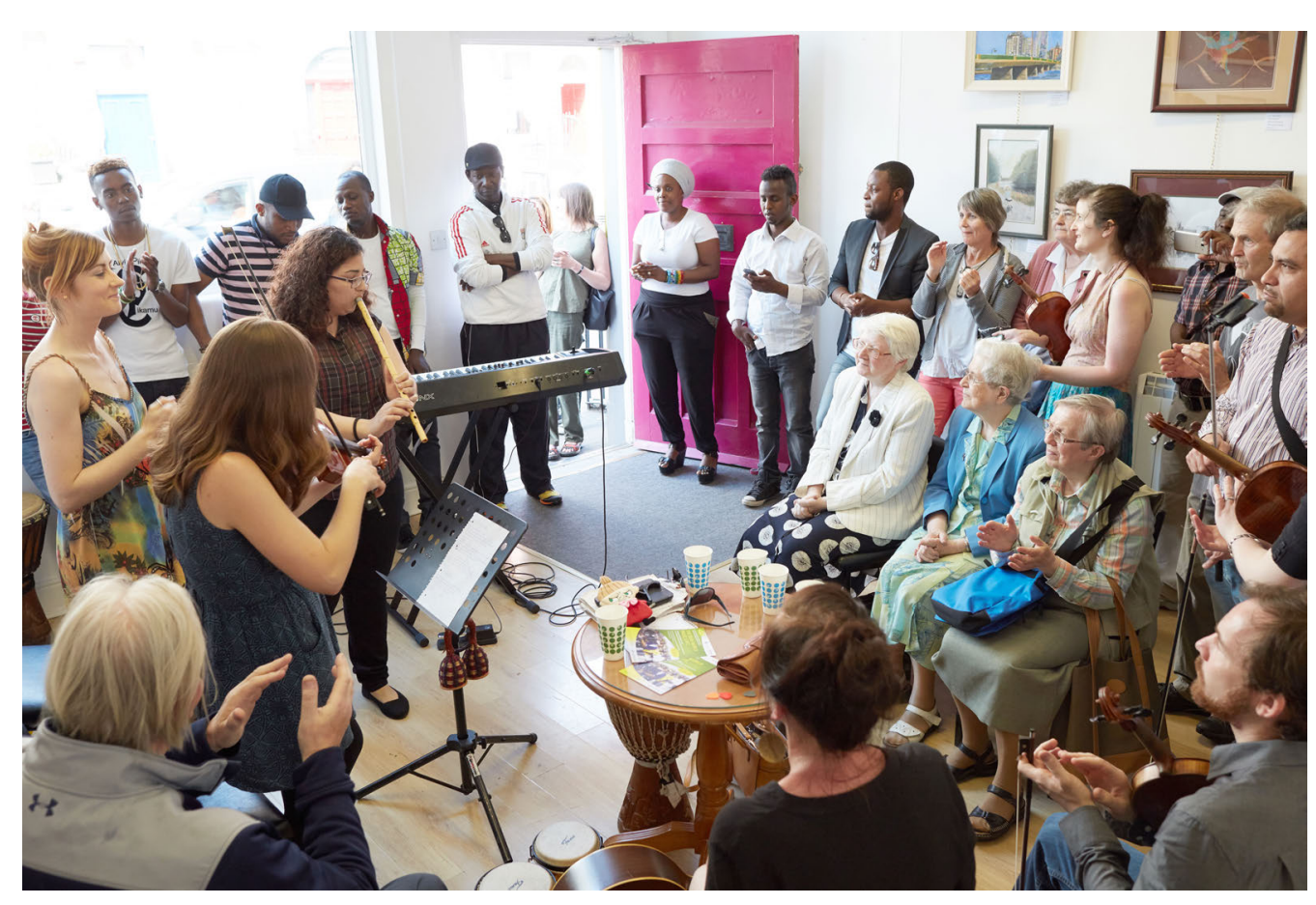

Figure 3. Irish World Music Café

(Photograph by Maurice Gunning)

Bennett (2012) reminds us that the expansion in the use of mobile internet and social media have changed live music engagement in recent years and further blurred the lines between artistic experience, participation, communication, and documentation. Through an analysis of fans of touring artists such as U2 and Tori Amos, she demonstrates how fans use technology to find each other and connect at live shows, to tweet and text live events to each other and to other fans not at the live events, to insert themselves into the performance through selfies and recordings. Bennett argues that 


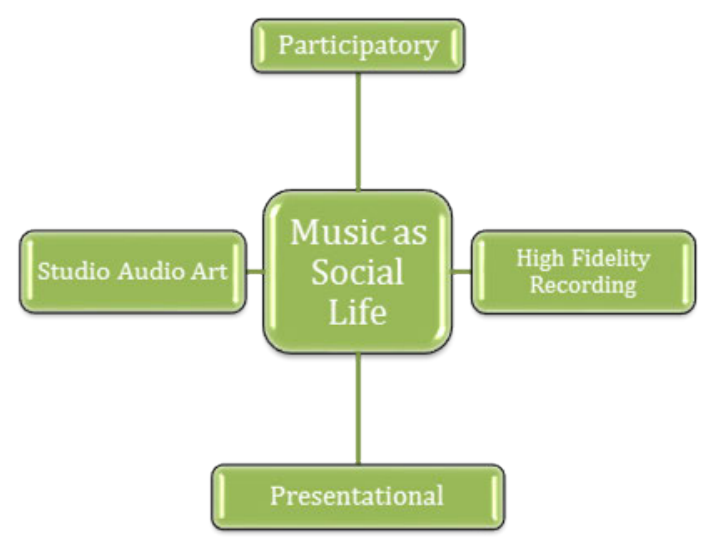

Figure 4. Turino's Categories of Music as Social Life

these activities contest and reshape the boundaries of what constitutes live and recorded performance.

Similarly, Irish performance artist Áine Phillips (2012) argues persuasively for the role of the videographer as a co-creator in performance art. The video, she suggests, acts as the "subconscious" of the performance, which can "elaborate another layer of meaning" allowing the live performance to be "enhanced, developed and transformed in new ways" (p. 11). Still photography also opens up what Phillips calls a "mysterious, open space" (p. 16) into which the viewer can project imagination, while video tends to try to convince us of the veracity of events. Boston-based performance artist Marilyn Arsen argues that this same artistic engagement between live performance and recording can happen when the recording is archival or documentary. The use of storytelling or narrative techniques, for example, can allow the foreground of performance and the background of commentary and context to merge into a single presentational piece of recorded art (Phillips, 2012). Young artists in particular are increasingly drawn to using video as part of their creative process, often developing expertise and sophistication in their ubiquitous use of social media and online applications.

For all these reasons, video recording now plays an important companionship role with many live performance events. The two video recordings included in this submission will be discussed in light of these observations as well their potential role in contributing to positive social change in terms of sustainable integration.

\section{The Music Hub}

Learning Hub Limerick was established in 2007 to work in partnership with families, young people and educators to address high levels of education disadvantage experienced by communities in the north side of Limerick city. Dominic Chappell first became involved with the Hub as a project worker in 2014. A year later, he was hired as the studio coordinator with responsibility for running Music Hub Studios, an independent social enterprise functioning from within the Learning Hub:

Our focus is primarily audio recording and production although we do some video work as well as some community projects. The studio is available for hire and local musicians and bands come to the studio to record and rehearse on a professional basis. One example of our community work is the establishment of Limerick's Homeless Choir, open to clients of Focus Ireland, Novas and the Simon Community.

Chappell was also involved in the recording of Our Voice, written and performed by the Youth Advocate Programme Limerick participation group. ${ }^{6}$ He was introduced to the Irish World Music Café by singer, songwriter, artist, and fashion designer, Julianne Hennelly. Hennelly is currently undertaking a Masters in Community Music at the Irish World Academy. She heard about the café and was immediately interested in becoming involved: 
I'm really interested in learning about other cultures. I just love that energy when all different types of people get together - it's so special.

As an accomplished singer in her own right, Hennelly initially participated in the café as a performer and songwriter. However, her work on the community music programme, as well as her sister's professional involvement with the Refugee Resettlement Initiative $^{7}$ led her to developing a community placement with the Syrian community. Here, she began to meet musicians and singers whom she subsequently invited to perform at the café:

My sister was bringing the Syrian families to a musical evening ... Moustafa stood up and he sang - he was not a bit shy at all - he was really good with the small kids and that stuff - the music café was going on maybe a week later and I invited him to that ... his mother is an amazing singer and that is where he learned all the old Arabic songs and his sister is an amazing singer as well. ${ }^{8}$

In earlier professional work with Artsquad, ${ }^{9}$ Hennelly collaborated closely with a videographer. Her background in visual art as well as music enhanced her appreciation of the collaborative potential of music and video: "you do these events, but when someone captures them really well, it's magical."

Hennelly contacted Chappell about the possibility of recording the next world music café. Chappell volunteered his own service and those of the students on placement at the learning hub:

Many placement students from colleges around Ireland come to the Learning Hub. Some are involved in all of the general activities at the Hub and some do their internship solely with Music Hub Studios. When organising the filming of the cafe at the end of last year, I tasked three students from UL's Music, Media and Performance Technology undergraduate course to complete the initial recording. An intern from the Video production course at LCFE took over the initial part of the editing process, which I then finished before sending it on to Julianne.

Julianne helped to identity three musical items for the final, edited recording. The first features Moustafa's initial public performance. The second captures the music of the Irish traditional musicians who kick-off each café with some tunes. The third features the Elikya ensemble; the ensemble which would become the focus of the second video recording. The recording also includes still photography. The combination of still and moving imagery, as well as music audio, captures some of the affective and communicative dimensions of the café. While the café has been in a brief hiatus due to building works in the venue, our plan is to use the recording to help promote and disseminate a flavour of the café experience: the diverse musical performances, the sense of community as well as feelings of belonging, inclusion and mutual cultural learning.

\section{Elikya: Hope}

Since its inception, the primary music partner of the Irish World Music Café has been the Elikya ensemble. Elikya is one of the longest established African music groups in Ireland. Based in Limerick, it has a track record of educational and musical leadership in the promotion of African musical culture in general and Congolese culture in particular.

In March of 2017, Andrew Nathan Roberts, ${ }^{10}$ a student on the MA Journalism at the University of Limerick contacted me. Roberts studied Screen and Media in Melbourne before coming to Ireland. In the context of these studies, he was introduced to documentary filmmaking and became interested in how extensive and experimental documentary film could be. In coming to Ireland to study journalism, he felt drawn to working with new migrant communities here:

My parents were migrants to Australia, so it's in my background really. My aunty lives here and knew some people who were doing work in that field. It seemed natural to want to be involved. 


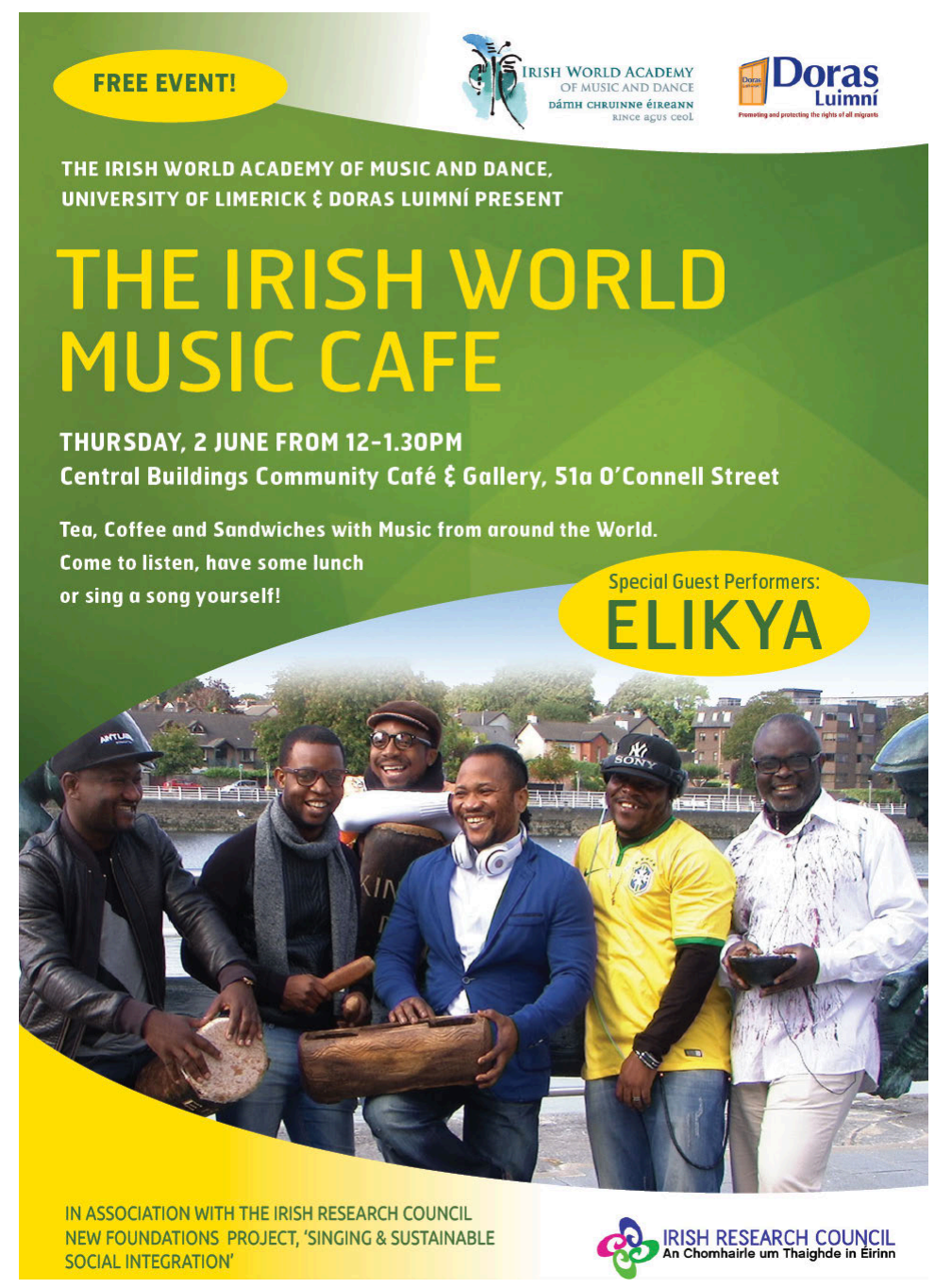

Figure 5. Irish World Music Café Poster

(Design, Joe Gervin)

Roberts contacted me to explore the possibility of doing a piece on the café. Although the next café turned out be too late for his deadline, he was drawn to working with Elikya and learning more about their story. Roberts' recording combines musical soundscapes with narrative, charting the story of Elikya's origins, identity and aspirations. In reflecting on the recording, he notes being struck by:

...[T] he magic of the performance and the honesty in the music. Elikya aren't trying to fool anyone or be something that they are not. That is really refreshing, and just being in a room with them demonstrates that. If I could present even $10 \%$ percent of that in the video format, then I think I'm doing well.

Roberts has worked in the space between documentary and artistic recording before. With Phillips (2012) he notes the collaborative nature of live performance and recording, as well as what each medium can contribute to the experience:

I think it's important to not get in the way of energy of the performer. It's about capturing small moments that can provide an insight into the how it would feel if you were in the room... The camera can get closer to the performer and "trap" little moment in close-ups and in tiny fragments of detail that might escape the general viewer in attendance. There is magic in these moments that demonstrate an intimacy in how an artist performs. 


\section{Conclusion}

The efficacy of the video recordings must be experienced and evaluated rather than evidenced, and it is not the point of this paper to do so. However, this paper has drawn attention to those aspects of the Irish World Music Café and the Elikya documentaries which foreground the valuing of alternative cultural cohorts and their contribution to social integration. In these concluding remarks, two key ways in which live and recorded performances play a role in the contemporary debate around social inclusion will be suggested. It is also argued that social inclusion is core to any articulation of a just society and art has a key part to play in this articulation.

Rawls' (1971) classic theory of social justice is predicated on what he calls the "liberty" and the "difference" principles. The liberty principle proposes equal, aspirational access to justice. This exists primarily in the ideological and legal realm. The difference principle recognizes that in the real world, justice is distributed unequally and actions are required to promote equality of access to justice. The difference principle exists in the political, socio-economic realm. Therefore, social justice depends on activist politics to promote justice as fairness in the world. Reisch $(2002,2007)$ both enriches and complicates this view of justice by noting the cultural nuances of fairness, as well as by articulating the realms through which social justice operates. Justice depends on fair access to wealth, health, and social redress. It is hindered by poverty, poor physical or psychological well-being, or the inability to access systems of redress.

It is these systems of redress, which preoccupy Turino's (2008) reflections on music and advocacy, making a case for world music events and education as agents of cultural change. He suggests that culture manifests in a number of inter-relating layers. What he calls cultural formations are the primary socializations we are all born into. Cultural cohorts are self-selected and often select their cultural activities as part of their selfidentity. People who attend the Irish World Music Café form a cultural cohort. Mainstream or prevailing music forms are an important component of a dominant cultural formation. Creating a cultural cohort around more diverse and less dominant cultural expressions provides the basis for alternative values through alternative experiences and the possibility of cultural change. In other words, performance events such as the Irish World Music Café expose its participants - both live and online - to alternative cultural experiences and provide a metaphoric model of a more culturally diverse and fair society (Turino, 2008).

Similarly, borders are breaking down between live and recorded performance. The ways in which these media respect the uniqueness of each, complement each other and at times merge into a singular artistic experience is one of the most interesting and pervasive cultural expressions of our time. Harnessing its actual and metaphoric potential as an example of integration through diversity as well as unity through difference is one of the ways in which this work hopes to contribute to a more just and creative world.

\section{Notes}

1. For further information on the Singing \& Sustainable Social Integration initiative, see http://www.ul.ie/engage/node/1791

2. See for example https://www.cfplist.com/cfp.aspx?cid=11362 (accessed 21 June 2017) for the use of this term in the US. It has developed as a way of eliminating qualifying descriptors such as 'based', 'as', 'led', 'through' etc., which are often used to prescribe a specific relationship between 'practice' and 'research', while maintaining the centrality of practice which is not present in terms such as 'artistic research'. See for example Nelson (2013) and Nimkulrat (2007) for a discussion of terminology describing this approach to research.

3. Doras Luimní is an independent, non-profit, non-governmental organisation working to support and promote the rights of all migrants living in Limerick and the wider Mid-West region (see http://dorasluimni.org/) 
4. See http://www.irishworldacademy.ie/category/outreach/ for further information on Sanctuary at the Irish World Academy, University of Limerick.

5. See http://www.lylianfotabong.com/first-irish-world-music-cafe-opens-in-limerick/

6. For more information on this project, see http://www.yapireland.ie/what-we-do/photosvideos/photos/yap-limerick-participation-group-our-voice.html

7. The Refugee Resettlement initiative supports the resettlement of Syrian and Iraqi refugees into the community. It is delivered by PAUL Partnership in cooperation with other statutory and community agencies . PAUL Partnership is an organisation made up of communities, state agencies, social partners, voluntary groups and elected representatives. It works with local communities that have benefited least from economic and social development and aims to promote social inclusion and improve the quality of life of people living in these communities (see https://www.paulpartnership.ie/refugee-resettlement-initiative/).

8. Moustafa and his family shared parts of their family story in an interview with the Limerick Leader newspaper - see http://www.limerickleader.ie/news/home/230746/syrian-familyresettled-in-limerick-speak-of-isis-terror-in-aleppo.html

9. Established in 1997, Artsquad provides training in community arts skills through the support of Mayo Council Council (see http://www.mayococo.ie/en/Services/ArtsOffice/Artsquad/ )

10. A show-reel of Robert's work is available at https://www.youtube.com/ watch?v=0UwIy_KBZ9A\&t $=12 \mathrm{~s}$

\section{References}

Ahlquist, K. (2006). Chorus and community. Champaign, IL: University of Illinois Press.

Bannerman, C., Sofaer, J., \& Watt, J. (Eds.). (2006). Navigating the unknown: The creative process in contemporary performing arts. London, England: University of Middlesex Press.

Bennett, L. (2012). Patterns of listening through social media: Online fan engagement with the live music experience. Social Semiotics, 22(5), 545-557, https://doi.org/10.1080/ 10350330.2012.731897.

Cohen, M. S., \& Coady, J. D. (2009). A protocol for cross-cultural research on the acquisition of singing. Annals of the New York Academy of Sciences, 112-115, https://doi.org/10.1111/ j.1749-6632.2009.04771.x.

Ford, J. K. (2003). Preferences for strong or weak singer's formant resonance in choral tone quality. International Journal of Research in Choral Singing, 1(1), 29-47.

Grape, C., Sandgren, M., Hansson, L. O., Ericson, M., \& Theorell, T. (2003). Does singing promote well-being? An empirical study of professional and amateur singers during a singing lesson. Integrative Physiological and Behavioural Science, 8(1), 65-74.

Jäncke, L. (2008). Music, memory and emotion. Journal of Biology, 7(6), 21, https://doi.org/ 10.1186/jbiol82.

Leavy, P. (2009). Method meets art. New York, NY: The Guilford Press.

Nelson, R. (2013). Practice as research in the arts: Principles, protocols, pedagogies, resistances. Hants, England: Palgrave.

Nimkulrat, N. (2007). The role of documentation in practice-led research. Journal of Research Practice, 3(1), 1-8, http://jrp.icaap.org/index.php/jrp/article/view/58/132.

Odena, O. (2009). Early Music Education as a Tool for Inclusion and Respect for Diversity. Study Paper for the Bernard van Leer Foundation. Project Report. Brighton, UK: University of Brighton and Bernard van Leer Foundation. Retrieved from http://eprints.gla.ac.uk/ $76420 /$.

Ó Laoire, L. (1997). Traditional song in Ireland: Living fossil or dynamic resource? The Phenomenon of Singing, 1, 161-170.

O'Shea, H. (2007). Getting to the heart of the music: Idealizing musical community and Irish traditional music sessions. Journal of the Society for Musicology in Ireland, 2, 1-18. 
Parncutt, R., \& Dorfer, A. (2011). The role of music in the integration of cultural minorities. In I. Deliège \& J. Davidson (Eds.), Music and the mind:Essays in honour of John Slobada. New York: Oxford University Press.

Phelan, H. (2001). Anáil Dé / The breath of God: Music, ritual and spirituality. Dublin, Ireland: Veritas Publications.

Phelan, H. (2002). Comhcheol. Film documentary commissioned by the Sanctuary initiative at the Irish World Academy. Produced by S.M.V.I. Productions.

Phelan, H. (2003). Anáil Dé, Breath of God Festival of World Sacred Music. Film documentary commissioned by the Sanctuary initiative at the Irish World Academy. Produced by McGlynn Brothers Productions.

Phelan, H. (2006). Borrowed Space, Embodied Sound: The Sonic Potential of New Ritual Communities in Ireland. Journal of Ritual Studies, 20(2), 19-32, https://doi.org/10.1093/ acprof:oso/9780190672225.001.0001.

Phelan, H. (2007). Let Us Say Yes: Music, the Stranger and Hospitality. Public Voices, 9(1), 113-124, https://doi.org/10.22140/pv.206.

Phelan, H. (2008). Practice, Ritual and Community Music: Doing as Identity. International Journal of Community Music, 1(2), 143-158, https://doi.org/10.1386/ijcm.1.2.143_1.

Phelan, H. (2009). Religion, music and the site of ritual: Baptismal rites and the Irish Citizenship Referendum. International Journal of Community Music, 2(1), 25-38, https://doi.org/10.1093/acprof:oso/9780190672225.001.0001.

Phelan, H. (2012). Sonic hospitality: Migration, community and music. In G. McPherson \& G. Welch (Eds.), Oxford handbook of music education (pp. 168-194). Oxford, England: Oxford University Press. https://doi.org/10.1093/acprof:oso/9780190672225.003.0007.

Phelan, H. (2017). Singing the Rite to Belong: Music, Ritual and the New Irish. Oxford and New York: Oxford University Press. https://doi.org/10.1093/acprof:oso/ 9780190672225.003.0005.

Phelan, H., \& Kuol, N. (2005). Integration and service provision: Survey of persons with refugee and leave to remain status in Limerick city. Limerick, Ireland: Limerick City Development Board.

Phillips, Á. (2012). Live art \& videotape. Printed Project, 15, 11-22.

Parker, B. (2009). Good vibrations: The singing voice. Baltimore, Maryland: The John Hopkins University Press.

Rawls, J. (1971). A theory of social justice. Cambridge, MA: Harvard University Press.

Reisch, M. (2002). Defining social justice in a socially unjust world. The Journal of Contemporary Human Services, 83(4), 343-354, http://dx.doi.org/https://doi.org/10.1606/ 1044-3894.17.

Reisch, M. (2007). Social justice and multiculturalism. Studies in Social Justice, 1(1), 67-92.

Thacker, V. (2012). Experiencing the moment in song: An analysis of the Irish traditional singing session. Ethnomusicology Review, 17, http://ethnomusicologyreview.ucla.edu/ journal/volume/17/piece/601.

Turino, T. (2008). Music as social life: The politics of participation. Chicago, IL: University of Chicago Press.

Vogel, A. (2005). Film as a subversive art. London, England: C.T.Editions.

Weinstein, D., Launay, J., Pearce, E., Dunbar, R. I. M., \& Stewart, L. (2016). Group music performance causes elevated pain thresholds and social bonding in small and large groups of singers. Evolution and Human Behavior: Official Journal of the Human Behavior and Evolution Society, 37(2), 152-158, http://doi.org/10.1016/j.evolhumbehav.2015.10.002.

Welch, G. F., Himonides, E., Saunders, J., Papageorgi, I., \& Sarazin, M. (2014). Singing and social inclusion. Frontiers in Psychology, 5, 803, http://doi.org/10.3389/fpsyg.2014.00803. 


\section{Web sources}

Doras Luimní http://dorasluimni.org/

Global Trends, A Report of the UNHCR, the UN Refugee Agency https://s3.amazonaws.com/ unhcrsharedmedia/2016/2016-06-20-global-trends/2016-06-14-Global-Trends-2015.pdf

Irish World Academy of Music and Dance, University of Limerick Sanctuary Outreach Programme http://www.irishworldacademy.ie/category/outreach/

Mayo Artsquad: http://www.mayoartsquad.ie/about.php

Music Hub Studios https://www.musichubstudios.ie/

Paul Partnership Refugee Resettlement: http://www.paulpartnership.ie/refugee-resettlementinitiative/

'Syrian family resettled in Limerick speak of 'Isis terror' in Aleppa' 13 January 2016 in the Limerick Leader http://www.limerickleader.ie/news/home/230746/syrian-family-resettledin-limerick-speak-of-isis-terror-in-aleppo.html

UL Engage: Singing and Sustainable Social Integration Project: http://www.ul.ie/engage/ node/1791

\section{Live and On-Line Interviews}

Dominic Chappell (29 May 2017)

Julie Hennelly (26 April, 2017)

Andrew Nathan Roberts (26 April 2017) 